\title{
Camestáo
}

\section{Análise da paisagem cafeeira representada: visões interdisciplinares}

\author{
Silvia Maria do Espírito Santo \\ Doutora;Universidade de São Paulo, Ribeirão Preto, SP, Brasil; \\ silesan@usp.br
}

\begin{abstract}
Resumo: O presente artigo opera a leitura do documento a partir dos elementos apriorísticos da análise da imagem da paisagem, frente à experiência empírica, subsidiária da observação do objeto documental selecionado. Neste estudo, apresentam-se três objetivos: a forma de coleta de informações dos documentos relativos a acervos históricos, a análise dos contextos culturais e os argumentos que apontam para uma reflexão da articulação interdisciplinar entre áreas das humanidades. Para esta pesquisa, aplica-se o método quadripolar no estudo dos contextos culturais, entre os polos morfológico, prático, epistemológico e teórico. Conclui-se que, ao enfatizar a articulação e elementos advindos da "dinâmica investigativa quadripolar", permite-se problematizar a leitura linear da paisagem na temática do Café para novas abordagens científicas e culturais.
\end{abstract}

Palavras-chave: Paisagem. Café. Análise Documental. Método Quadripoloar

\section{Introdução}

O estudo apresenta um breve panorama analítico em torno da imagem da paisagem representada em suas várias leituras. Busca-se o exercício teórico e operacional com a finalidade de agregar experiência a processos que se pautam nos fundamentos da Ciência da Informação. Todavia, é no método quadripolar que encontramos sustentação para o estudo da "fenomenalidade humana e social" e que se completa na dinâmica operativa quadripolar, se considerarmos a documentação arquivística como primordial para o estudo desse fenômeno e a potencialidade desse quadrante argumentativo.

O estudo da informação referente à "paisagem cafeeira" parte do modelo científico baseado no processo de reconhecimento do suporte documental, da técnica aplicada na confecção da imagem e da análise da identificação dos elementos semânticos contextuais presentes na interpretação da imagem (MONTEIRO; ROSA; VIDOTTI, 2020). A partir da produtividade e da eficiência de recuperação, reconhecemos que esta preocupação é disponibilizada 
na historiografia da área da Ciência da Informação, nomeadamente na linha de estudos sobre o desenvolvimento tecnológico a serviço do acesso e da complexidade conceitual, no entrelaçamento entre o produto informação estruturada (informação arquivística) e o consumo informacional.

A complexidade teórica espelhada na abordagem do desenvolvimento científico e tecnológico esteve em pauta na Ciência da Informação quando derivada nas áreas afins (Arquivística, Museologia e Biblioteconomia). Além dos fluxos informacionais, objetiva-se a busca da precisão terminológica e das disponibilidades possíveis em processos mediadores adensadas na análise terminológica entre diferentes áreas ${ }^{1}$.

Há mais de seis décadas, ainda no século XX, as práticas inovadoras científicas do acesso ao conhecimento - como as diretrizes para a construção do conhecimento científico - partiram da relevância do conceito de informação e do domínio dos métodos tecnológicos de controle da densidade informacional da produção científica. Essas foram seguidas por teorias advindas das ciências exatas, bem como da teoria da comunicação e difusão do conhecimento, caracterizando, assim, um modelo de análise e disponibilização das informações. Portanto:

Dessa forma, ao tratar dos programas de pesquisa na área, González de Gómez (2000) argumenta que a Ciência da Informação recebe das ciências humanas seu traço identificador e defende a ideia de que ela se articula a partir de um caráter poliepistemológico: ela articula a produção de um conhecimento semântico-discursivo (ligado a conhecimentos culturais e de significação, relativos a métodos da antropologia e da lingüística); um conhecimento metainformacional (relativo à regulação dos ciclos e fluxos de informação, com métodos da administração, gestão e política); e um conhecimento infraestrutural (relativo à dimensão técnica e tecnológica, que articula métodos da computação e da economia) (ARAÚJO, 2014, p. 70).

Assim, tais saberes se erigirão por meio dos paradigmas surgidos na última década devido à importância dos processos de como se dá a construção do conhecimento nas esferas de coleta, seleção, avaliação e armazenamento das informações sob o ponto de vista da produção do conhecimento no âmbito da ciência, tecnologia e informação (CORSATTO; HOFFMANN, 2015). Almeja- 
se, então, que o presente texto, associando os conceitos derivados na relação processual da construção do conhecimento multidisciplinar inseridos nos pressupostos fornecidos pela História Cultural, abarque tanto a significação terminológica da planta cafeeiro quanto as especificidades de circulação e significados do produto café, visando subsidiar uma compreensão do contexto e despertando reflexões quanto à representação social da paisagem rural a partir dos pressupostos metodológicos expostos até aqui.

No que tange à paisagem representada, esta não será suficientemente conhecida e tampouco aprofundada na Ciência da Informação ou nos métodos de indexação se as razões de sua própria percepção são desconsideradas, ou seja, as dimensões da vivência humana que, de certo modo, viabilizam um e não outro entendimento do objeto diante de nós - estejam tais fatores relacionados aos sentidos memoriais, históricos, colecionistas documentais ou não - ou a suas particularidades culturais nos registros usuais e dos processos de recuperação da informação para fins científicos e culturais.

A partir do estudo em torno do tema "café", diferentes saberes são mobilizados. O próprio termo "tema" evidencia-se sintomático e infringente dos sentidos das normas a que se relacionam na Ciência da Informação quando tomado pela precisão informacional isolada. Assim, dentro do consenso da organização documental, ou seja, das normas da indexação específica (atribuição, por termos, derivativa, seletiva, exaustiva, citação, ponderada), almeja-se que as reflexões ensejadas ilustrem o direcionamento das etapas da metodologia voltada a descrever a contribuição da observação temática.

A descrição da paisagem a partir dos procedimentos da indexação por atribuição de categorias analíticas será, pois, tomada como roteiro básico do exercício de indexação da imagem da paisagem do tema "café", considerando as atribuições de sua dimensão expressiva (MANINI, 2002) e os saberes da semiótica, área que "acaba de uma vez por todas com a idéia de que as coisas só adquirem significado quando traduzidas sob a forma de palavras" (PIGNATARI, 2004), oportunizando o olhar científico e interativo entre as áreas da história, das ciências agrárias, da geografia, da arte, entre outras. 
Ao mesmo tempo em que a interdisciplinaridade amplia o leque de leituras possíveis de um mesmo fenômeno, a metodologia arquivística, se vista como integradora entre informação e produção do conhecimento - através dos procedimentos da seleção em grupo, série e subséries documentais - contribui fortemente para eliminar a confusão da organização informacional ao diferenciar procedência e autoria, análise e avaliação e destino sistêmico da imagem, por exemplo.

A partir deste cruzamento de saberes, emerge a hipótese de que, se essa paisagem é vivenciada na criação (ou até mesmo na apropriação) por parte do indivíduo que mobiliza relações lógicas da realidade para a construção dos elementos que compõem tal paisagem, - tais como a linha do horizonte, o que está acima, abaixo e no centro do espaço recortado pelo olhar etc. - se operará, pois, uma extensão do sujeito na imagem, suas vivências perpassam a maneira como lê o mundo. Assim, pode a descrição conceitual da paisagem ser usada como ferramenta retroativa de análise histórica da paisagem?

Desde o século XVII, a imagem da paisagem se faz intensamente presente na iconografia brasileira, expandindo-se para novos meios de representação no século XIX, quando se configuram procedimentos técnicos a partir das mudanças ocasionadas pela paulatina industrialização do país. Nesses momentos, as áreas de investigação fartaram-se do registro de paisagem, reinventando-a em ambientes cenográficos, artísticos ou nas imagens reproduzidas nas banalidades da imprensa cotidiana ou das posições editoriais e comerciais. Apresentam-se, na presente pesquisa, três objetivos: a forma de coleta de informações dos documentos relativos a acervos históricos, a análise dos contextos culturais e os argumentos que apontam para uma reflexão da articulação interdisciplinar epistemológica, entre áreas das humanidades, no contexto organizacional dos arquivos e dos museus, representativos da temática paisagística do café. 


\section{Metodologia}

Nos últimos cinco anos, esta pesquisa acadêmica esteve sustentada por experiências empíricas com base na leitura de imagens de acervos analógicos e digitais relacionados ao tema "café". Nas etapas de seleção das bibliografias das áreas correlatas (arquivologia, biblioteconomia e museologia), priorizou-se as que consideram o documento como fonte do texto e da imagem, reconhecendose a limitação do estudo diante da grandiosidade explorada na historiografia brasileira e estrangeira para o estudo do fenômeno do produto café.

No manejo da leitura das imagens das paisagens, os procedimentos de pesquisa contaram com as premissas das possíveis variáveis da percepção, considerando o diálogo com o leitor frente às legendas textuais e o posterior isolamento da paisagem cafeeira. Delimitou-se como corpus inicial o conjunto de dezenas de capas dos Boletins da Superintendência do Serviço do Café (SEADE, 2018), datados considerando o período entre a década de 1940 e o ano de 1958, contemplando publicações de cartões postais, acervo pessoal e bibliografia de referência como universo da análise.

No caso de acesso à informação, esses procedimentos revelam-se problemáticos devido ao caráter polissêmico de qualquer imagem que se evidencia imediatamente ambígua, na melhor das hipóteses. A tentativa de domínio da imagem pela extração da palavra continua sendo um desafio para o leitor e para o indexador distantes no tempo e no espaço dos campos verdes, in loco, das neves desconhecidas ou das modificações territoriais desastrosas provocadas pelas bruscas transformações climáticas que afetaram de forma direta a paisagem do campo.

No momento deste primeiro olhar analítico sobre a imagem, revela-se a dimensão da virtualidade da fotografia, quando se pressupõe o documento científico e se dá lugar ao duvidoso e ao desconhecido, no nível da leitura da imagem em momentos de transformações radicais. Assim, estão a serviço da ciência e da produção agrícola, por exemplo, tanto os inúmeros sistemas de gerenciamento de imagens por satélite quanto os mecanismos tradicionais como a fotografia. 
Contudo, a análise da imagem pressupõe algo além da decodificação dos signos icônicos para sentidos linguísticos e vice-versa, pois percebe-se que, além da lógica do método da análise pré-icônica, impõe-se à análise a exigência de se entender o limite lógico dos elementos que a compõem (suporte, técnicas, processos químicos ou digitais etc.). Se a proposta do conhecimento da imagem da paisagem está em representar de forma condensada o seu conteúdo informacional, através da confecção de resumo, por exemplo, exercício amplamente utilizado nos programas que circulam no mundo virtual, oferece-se uma síntese de metodologias aplicadas a partir de Manini (2002) e Carvalho (1991), que figuram entre os autores mais citados da área da análise da imagem.

No que tange especificamente à análise da imagem da paisagem do café, faz-se necessário repensar o conteúdo informacional do produto e seu suporte de representação: se digital, se analógico e tantas outras determinações no papel da comunicação visual. A análise documentária fundamentada na política de acervo institucional, em que se destacam o contexto de produção e a proveniência de determinada coleção, conta com o levantamento dos dados biográficos, temáticos e relacionais da imagem representada. Completam-se, então, com a análise morfológica (aspectos técnicos e da composição), quando se propõem o desdobramento do tema e a seleção menos aleatória a partir de imagens de baixa resolução reproduzidas em papel.

Por ora, os tópicos e exemplos selecionados consideraram a questão da autoria e a contextualização como principais interesses determinados plenamente na área de conhecimento - a História da Arte -, utilizadas as categorias correspondentes da expressão e técnicas como fundamentos da representação.

\subsection{Campo teórico da imagem}

Para a compreensão do leitor, esclarecemos que as bases teóricas da presente pesquisa referem-se aos princípios que fundamentam a Ciência da Informação, cujos autores são citados, não necessariamente em tempo cronológico, mas notoriamente aqueles que estão inseridos nas discussões fertilizadas na teoria da imagem, da recuperação da informação e da análise documentária. Assim, sob o 
ponto de vista tecnológico, os autores Monteiro, Rosa, Vidotti (2020) e, especificamente, Corsatto e Hoffmann (2015), dão suporte para a reflexão na linha da gestão da informação e da inovação. Entre as autorias pioneiras no campo da Análise Documentária da imagem fotográfica e organização documental, estão Carvalho (1991), Manine (2002) e Macambyra (2019). Destacamos Carvalho (1991) na construção do olhar do ponto de vista da História e Cultura Material, o que contribuiu com o marco teórico das investigações produzidas dos anos de 1980 e 1990, no centro da valorização do estudo da fotografia, além do papel da ilustração, das categorias da Análise Morfológica, Icônica e Competência Narrativa. Em Manini (2002), da mesma forma, observam-se as categorias pré-iconográficas e pós-analíticas advindas da História da Arte de Gombrich (2000) e Panofsky (2007), e na Semiótica e linguística (PIGNATARI, 2004), em que os tratamentos analógicos e digitais das imagens fotográficas foram instrumentalizados à organização e recuperação informacionais dos acervos da imagem e do audiovisual (MACAMBYRA, 2019). A articulação dos argumentos exterioriza-se e fundamenta-se na demonstração desses elementos teóricos no Quadro I que, a seguir, ilustra os procedimentos adotados nos vários movimentos de leitura da paisagem cafeeira representada:

Quadro 1 - Processos para análise do conteúdo informacional de uma imagem

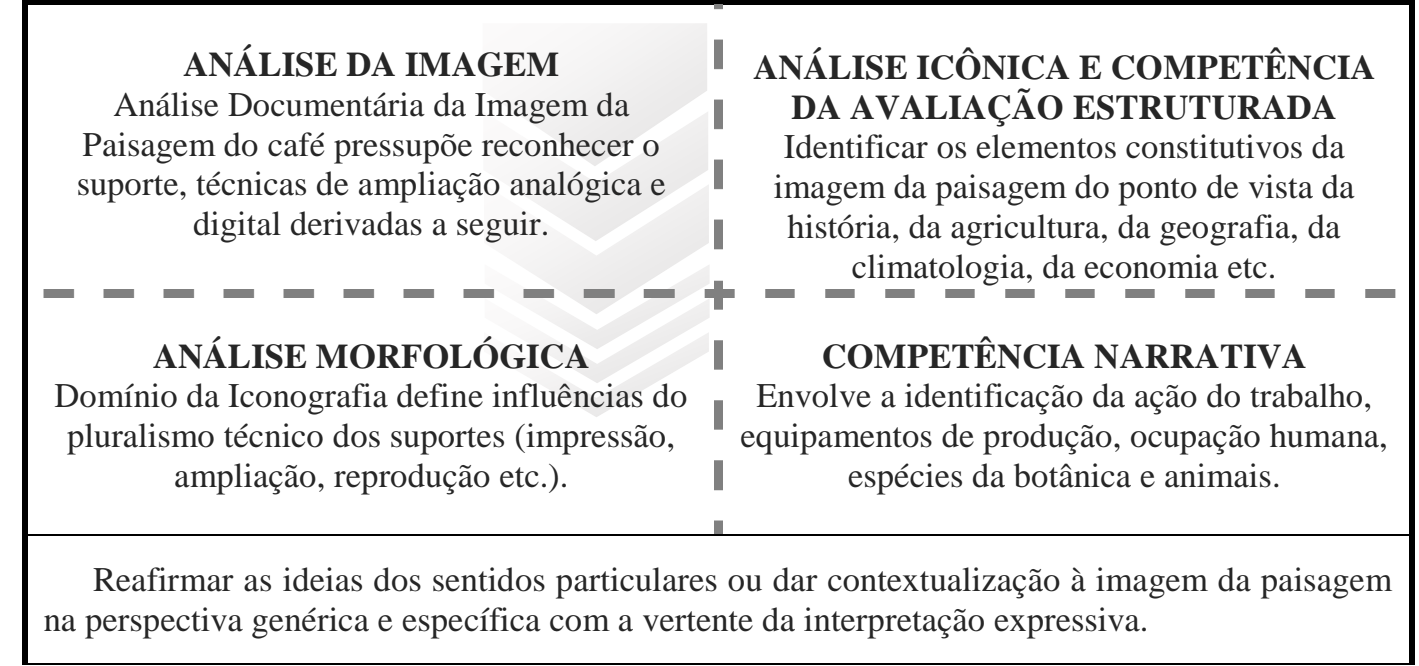


Perceber os ideais do sentido universal da imagem da paisagem inserida no contexto de criação em confronto histórico do desenvolvimento do suporte e da construção da imagem patrimonialista, isto é, dos conceitos, das leis e das chancelas do patrimônio cultural, uma vez que se trata de representação e em qual instância se inserem.

Fonte: elaborado pela autora, 2015.

As referências teóricas constituem a tentativa de construção de relações entre a tipologia da imagem da paisagem através da arte, tal como traçada por Gombrich (2000), e a análise icônica de fazendas de café por meio das referências produzidas na análise histórica das imagens da pintura com origem na fotografia, encomendadas por fazendeiros a pintores no século XIX no Brasil. Ao longo do tempo, sobretudo após a Segunda Guerra Mundial, as análises da arte reorientam-se à nova estrutura social e contribuem para superar o discurso de que a fotografia seria apenas um registro realista que subestima a visibilidade da imagem do café, limitando-o a sua dimensão de signo icônico e simplificando-o para afasta-lo do campo semântico onde representa um signo de poder.

Operacionalmente, no universo das fontes citadas, indicam-se neste período quatro tipologias básicas para a leitura da imagem: i) paisagem de produção; ii) paisagem urbana; iii) paisagem rural e iv) paisagem selvagem, as quais indiciam a proposição entre "um conjunto articulado de categorias e esquemas de percepção" (CARVALHO, 1991). Na pintura, o adensamento do pincel, a noção de perspectiva e a incidência da luz, luminosidade, espelhamentos e profundidade infinita dominam as imagens da natureza que se seguiram em meio às experimentações fotográficas a partir de 1840, acompanhando o movimento de busca da representação fidelizada para além dos limites técnicos das câmeras rudimentares, utilizando-se, por exemplo, da superposição de dois negativos para a construção de fotomontagens (CARVALHO, 1991).

Para ilustrar a metodologia, o que aqui não poderá ser longamente analisado, discutido ou considerado como indagações científicas, buscar-se-ão conceitos que se constroem e emergem a partir da paisagem do café, considerando-se que há uma conexão idealizada (platônica) na análise para a elaboração e o entendimento da imagem da paisagem. 
Na metodologia aqui proposta, respeita-se a fase pré-analítica definida por Manini (2002), que define quatro frases organizadas para transmitir sentidos, contribuir e dar início aos processos indexadores nos acervos da temática do café, identificadas na presente pesquisa:

1. esta imagem é paisagem (identidade e unidade);

2. estas imagens são paisagens (igualdades e diversidades comparativas);

3. estas imagens não são paisagens (contraditórias e distintas) e

4. estas imagens são todas paisagens (similares e complementares).

A fase pós-analítica pressupõe o reconhecimento multidisciplinar instrumental para a extração de termos descritores substantivos ao longo da leitura documental. Consideram-se, então, as etapas em que:

1. a descrição do conceito artístico e semiótico do tema paisagem evidencia-se sempre de forma sistemática na pintura e na fotografia;

2. a descrição dos elementos compositivos da imagem da paisagem quando indiciam equipamentos de dominação territorial, alguma prova de ostentação de poder científico, político, bélico e econômico (equipamentos modernos de medição, máquinas mecânicas da agricultura etc.), ou ainda os sentidos das significações da alma ou "retratos da condição humana" (distância, saudade, encontro, dor, esperança, rupturas etc.) a partir de um tratamento estilístico ainda que no âmbito do corpo textual (CAMUS, 2018) ${ }^{2} \mathrm{e}$

3. a descrição conceitual da área de domínio da Arte realiza-se considerando as diferentes formas da representação - por meio da pintura e fotografia. A paisagem é caracterizada a partir de descritores de autoria, data, local e técnica, sendo que estes campos atraem os elementos semânticos descritores suficientes para localizar a imagem no local em que se aplica a informação sistêmica nos diversos ambientes das instituições de domínio e curadoria de fundos das coleções, tais como os seus espaços museológicos, arquivísticos e bibliotecas.

Observa-se que a organização desses sistemas descritivos totaliza-se para cobrir as necessidades imediatas e mediatizadas dos programas associados ao 
conhecimento das representações coletivas de busca da informação. Todavia, requer do pesquisador a consideração quanto à complexidade da narrativa discursiva, do discurso icônico e das relações entre a produção e a contextualização histórica dos desdobramentos do tema-alvo. Portanto, no tratamento documentário da imagem da paisagem, nota-se a importância inconteste de relações estreitas com a arte, concebida como fonte de conhecimento que deve ser considerada ao cumprir o sentido interdisciplinar da análise da imagem para além da contemplação descompromissada.

Ao operar com a arte, a crítica analítica passou a entender que a imagem da paisagem pode ser compreendida como um conjunto articulado de categorias de percepção (CARVALHO, 1991). Desse pressuposto, percebe-se justamente o compromisso entre pintura e fotografia, ultrapassando a identificação dos elementos compostos nas formas tradicionais que, muitas vezes, reduzem a compreensão da fotografia apenas enquanto registro. Inevitavelmente, o cinema irá contestar os limites dessa interpretação esgotando-a na contribuição do movimento, do som e da fotografia. No cinema, a definição do "vazio" da representação da paisagem também ultrapassará os dilemas da indexação, sobretudo em função do domínio da linguagem cinematográfica, da produção industrial do cinema e dos conteúdos polissêmicos permitidos pelo movimento e pelo som (MACAMBYRA, 2009).

As manifestações das artes contribuíram para hierarquizar a informação na narrativa dos contextos da imagem, ou seja, aquilo que a História da Arte determina como as relações atemporais da interpretação passa a ser um ponto comum entre as compreensões multidisciplinares da análise da imagem. Passouse a observar sistematicamente como, por exemplo, a paisagem foi usada como meditação na China:

Os artistas chineses não iam para o campo sentar-se diante de algum motivo e esboçá-lo. Aprenderam inclusive a sua arte por um estranho método de meditação e concentração em que adquiriam primeiro a habilidade em "como pintar pinheiros", "como pintar pedras", "como pintar nuvens", estudando as obras de mestres famosos e não a própria natureza. Somente quando já tinham adquirido essa habilidade é que começavam a viajar e contemplar as belezas naturais a fim de cantarem os estados de espírito das paisagens (GOMBRICH, 2000, p. 153). 
Por seu turno, a criação de pinturas de paisagens na Inglaterra, através de modelos de criação de artistas como o pintor paisagista francês Lorrain (16001682), buscava aprimorar-se na reprodução do real. Ao longo do século XIX, os paradigmas do neoclassicismo e do romantismo culminam na invenção do conceito de "mais que o real". Nos anos seguintes, estabelece-se o questionamento da paisagem clássica e de seus valores subjacentes, apontando para o desenvolvimento crítico das formas expressionistas e abstratas (Fauvismos, Modernismo, Dadá, Futurismo, Surrealismo até a Arte Pop) ao longo do século XX, no que se convencionou chamar pós-moderno.

Para efeito de ilustração temática e referência conceitual da arte, interessa-nos abordar a imagem abaixo (Figura 1) visando qualificar a distinção entre a imagem pictórica e a imagem fotográfica.

Figura 1 - Detalhe de quadro à óleo intitulado "Embarque de café no Porto de Santos" (1911, 290x395 cm), de Oscar Pereira da Silva (1867-1939)

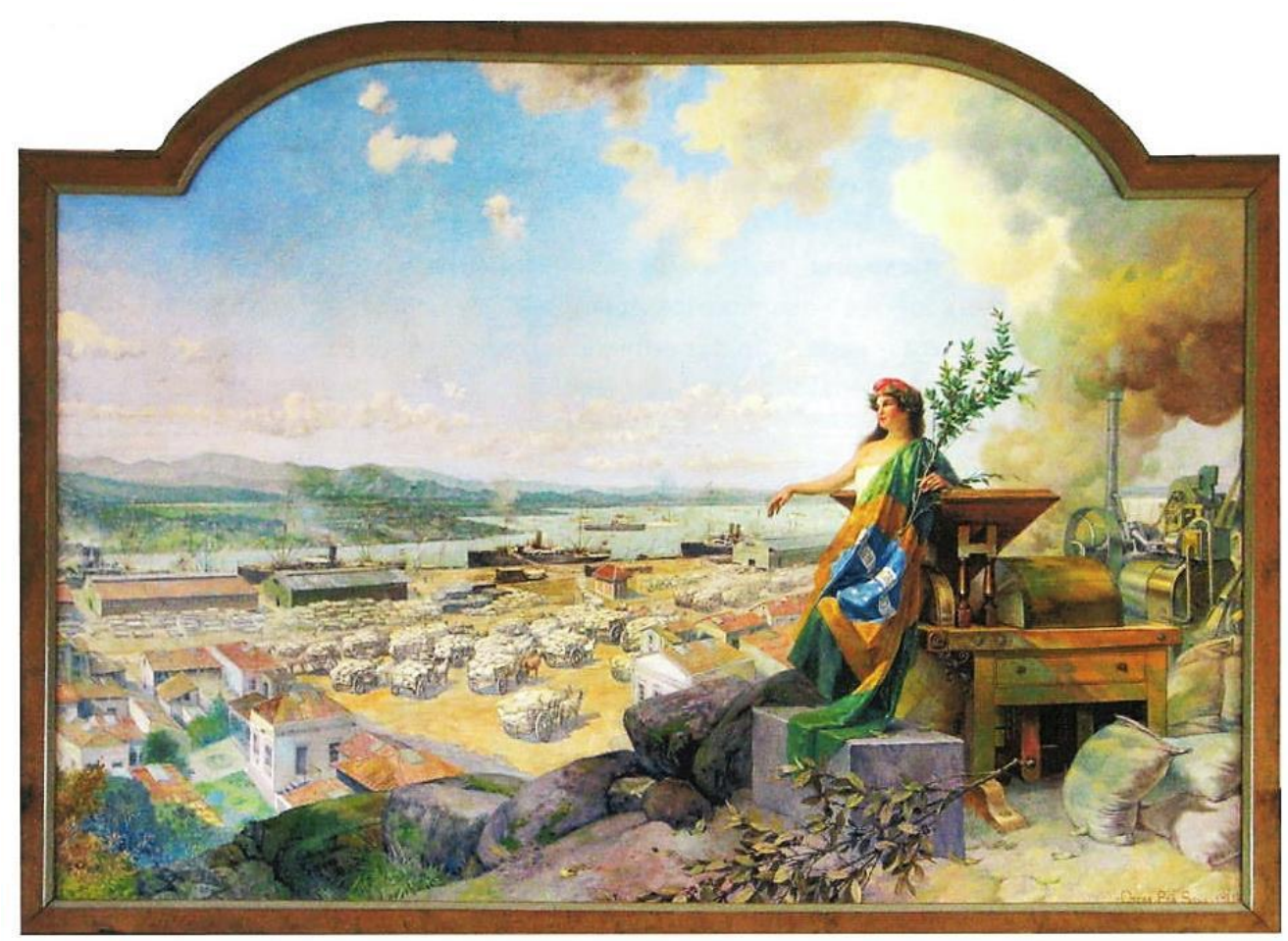

Fonte: Escola Superior de Agricultura Luiz de Queiroz, ESALQ-USP, Piracicaba, SP.

Obra em domínio público. Disponível em: http://agencia.fapesp.br/livro-comemora-os-50anos-dos-cursos-de-pos-graduacao-da-esalq/21267/. Acesso em: 17 dez. 2018.

A pintura "Embarque de café no Porto de Santos", de autoria de Oscar Pereira da Silva, foi exposta durante a exposição Universal em Turim, no ano de 
1911. Oscar Pereira da Silva era paisagista e, como especialista, descreveu o panorama da imagem pictórica em planos sequenciais e domínio temático. Da observação crítica da pintura, depreende-se a ideia de que seria a representação artística da maior riqueza do país destinada à exportação. Em primeiro plano, percebe-se a referência a Ceres, vestida de branco e envolta na bandeira brasileira enquanto ostenta um galho de café em uma das mãos. A divindade apoia-se de forma explícita sobre uma máquina de beneficiamento e, deste ponto da colina, avista o Porto de Santos emoldurado por nuvens em meio a um clima de trabalho rentável e progresso.

Observado em detalhes, o Porto de Santos documenta-se fielmente: a tela revela os movimentos dos trabalhadores, o promissor mercado externo representado pelos navios atracados e prontos para carregamento da carga fruto da rica produção cafeeira. Também há uma disposição linear das sacas de café (espaço intermediário), que foram transportadas por numerosas carroças movidas à tração animal para percorrerem o trajeto da estação ferroviária ligada às fazendas produtivas (espaço rural das fazendas - glebas, terreiros, campos) e ao porto para escoamento ao mercado exportador (espaço marítimo) e consequente destino final (espaço urbano das cidades - lojas, barracas, mercados, ruas).

\section{Resultados e discussão}

Com base nos percursos propostos na bibliografia consultada, realizou-se a leitura das imagens das localidades e paisagens do café no acervo mencionado. Considerou-se os aspectos da leitura frontal da imagem representada da paisagem do café no auge da produção cafeeira, a imagem panorâmica e centralizada com forte apelo estético estendendo-se em sentidos que significam ações do trabalho e chamam a atenção pelo lastro da ação do fotógrafo na construção da imagem focada na representação dos movimentos braçais, ostensivos na demonstração de progresso, e as nuances presentes dentro dos atributos tanto da paisagem rural da produção (plantio, colheita, secagem nos terreiros, ensacamento, transporte) quanto da paisagem urbana da produção (transporte, estocagem e armazenamento, comércio). 


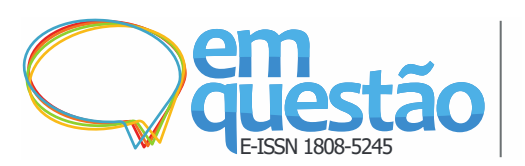

Análise da paisagem cafeeira representada: visões interdisciplinares

Silva Maria do Espírito Santo

A abrangência dos conceitos de paisagem no contexto rural e urbano, por exemplo, pode indicar heranças, concentração de renda, transformações ou intervenções na natureza, fatores da migração e a lógica da economia cafeeira (BENINCASA, 2003) representada na composição da produção agrária por meio dos grandes terreiros como os do Vale do Paraíba fluminense e paulista, as propriedades menores como no sul de Minas Gerais e São Paulo, possíveis devido à abundância da água em rodas d'água e estruturas como serraria, monjolo, casa de máquinas de café, usinas de energia, currais, retiros, elementos construídos ou equipamentos característicos das fazendas do século XIX.

Assim, a representação da imagem está baseada na criação de classes para agrupamento semântico a partir de parâmetros objetivos e subjetivos, fazendo o uso operacional de metáforas e adjetivos que objetivam, na identificação dos espaços, dar sentido simbólico ao que se lê (Quadro 2).

Quadro 2 - Construção simbólica dos espaços associados à representação da imagem do café

\begin{tabular}{|c|c|c|c|c|}
\hline $\begin{array}{c}\text { REPRESENTAÇÃO } \\
\text { DA IMAGEM }\end{array}$ & autor & técnica & data & local \\
\hline $\begin{array}{l}\text { EXTRAÇÃO DE } \\
\text { TERMOS }\end{array}$ & \multicolumn{2}{|c|}{ divisão por categorias } & substantivos & adjetivos \\
\hline CLASSES & \multicolumn{2}{|c|}{ corredores } & \multicolumn{2}{|c|}{ circulação } \\
\hline ESPAÇO & território & $\begin{array}{l}\text { regional } \\
\text { territorial } \\
\text { localidades }\end{array}$ & $\begin{array}{c}\text { capital } \\
\text { produção } \\
\text { intermediário }\end{array}$ & $\begin{array}{l}\text { instituição } \\
\text { circulação } \\
\text { imagem }\end{array}$ \\
\hline PRODUÇÃO & \multicolumn{2}{|c|}{$\begin{array}{l}\text { intermediário } \\
\text { fazendas } \\
\text { agentes do campo } \\
\text { agente da saúde } \\
\text { agentes financeiros } \\
\text { agentes religiosos }\end{array}$} & $\begin{array}{c}\text { agentes do } \\
\text { governo } \\
\text { agente político } \\
\text { agente do controle } \\
\text { agentes do } \\
\text { comércio } \\
\text { agente da } \\
\text { comunicação }\end{array}$ & $\begin{array}{c}\text { registro } \\
\text { documental } \\
\text { econômica } \\
\text { marítimo } \\
\text { depósitos } \\
\text { terrestres } \\
\text { mercado } \\
\text { armazéns } \\
\end{array}$ \\
\hline $\begin{array}{c}\text { PERCEPÇÃO DO } \\
\text { LUCRO }\end{array}$ & $\begin{array}{l}\text { masculinidade } \\
\text { virilidade } \\
\text { elegância } \\
\text { porto } \\
\text { viagem }\end{array}$ & $\begin{array}{c}\text { ereto } \\
\text { retidão } \\
\text { racionalidade } \\
\text { produção } \\
\text { riqueza }\end{array}$ & $\begin{array}{c}\text { exótico } \\
\text { sala } \\
\text { escritório } \\
\text { chefias locais } \\
\text { reuniões }\end{array}$ & $\begin{array}{c}\text { trabalho braçal } \\
\text { família } \\
\text { escritório }\end{array}$ \\
\hline
\end{tabular}




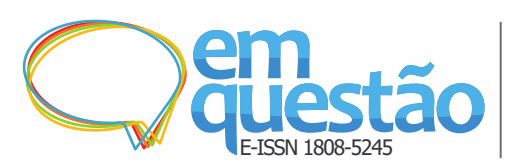

\begin{tabular}{|ccccc|}
\hline & feminilidade & prejuízo & despojado & \\
PERCEPÇÃO DA & reprodução & isolamento & cozinha & trabalho manual \\
ATMOSFERA & desprezo & ruptura & igreja & família \\
& distância & perda & serviços locais & casa \\
& saudade & miséria & agrupamentos & \\
\hline
\end{tabular}

Fonte: elaborado pela autora, 2015.

O quadro acima permite notar que a principal entrada de informações coletadas é indicada na Representação da Imagem, segundo dados básicos descritivos (autor, técnica, data, local). A partir desse pressuposto, orientador e usual na extração de termos, procede-se à divisão de categorias simples, identificadas por substantivos e adjetivos. Então, optou-se por criar classes baseadas na palavra "espaço", ou "intensas passagens", (diferentes de "circulação") por entender que, assim, destina-se um sentido de fluidez às localidades em análise através de imagens. Nesse caso, o espaço é definido pelo território geográfico entre regiões diversas, reconhecendo-se que as demarcações do território implicam-se nas relações socioeconômicas permitidas pelo capital investido, de modo que registros documentais visualizados na articulação das fontes de pesquisa disponíveis ilustram essas relações intrínsecas.

As análises da imagem da paisagem do café, em perspectiva e determinada pelos pontos de fuga na constituição da imagem, insistem na tentativa de iludir e, de certo modo, desviar o olhar do conjunto complexo de seus significados. Diluem ao julgamento do observador o que está presente nas lateralidades da imagem; no acanhamento do detalhe além do foco obtido pelo autor, constrói-se a imagem da paisagem. No universo das imagens sobre o produto café, verifica-se o reforço da presença da conquista do poder da terra, da fartura na quantidade do produto, do peso da hierarquia social, do maior ostentando ao menor, do trabalhador subserviente, da imposição política do domínio da produção cafeeira, da abundância reforçada pela criação da paisagem etc.

No Quadro 3, abaixo, percebem-se os principais eixos da organização espacial da produção cafeeira por meio da descrição das tipologias espaço, território e região: 
Quadro 3 - Organização espacial da produção do café a partir da representação da imagem

\begin{tabular}{|c|l|}
\hline ESPAÇO & $\begin{array}{l}\text { Terrestre, marítimo e espacial (espaço geográfico) - corredores das } \\
\text { construções, das casas, corredores das edificações; espaço rural das } \\
\text { fazendas - glebas, terreiros, campos; espaço urbano das cidades - lojas, } \\
\text { barracas, mercados, ruas; espaço marítimo. Espaço intermediário. }\end{array}$ \\
\hline TERRITÓRIOS & $\begin{array}{l}\text { Territórios - são imaginados, desenhados, medidos; relacionados à terra; } \\
\text { relacionados à política. }\end{array}$ \\
\hline REGIÃO & $\begin{array}{l}\text { Regionalidades - Região administrativa. Definidos no tempo por razões } \\
\text { socioeconômicas e políticas; região geográfica. Definidos no tempo por } \\
\text { razões socioeconômicas e políticas e naturais; região cultural. Definidos no } \\
\text { tempo por razões socioeconômicas e políticas e naturais; agentes (seres } \\
\text { humanos, trabalhadores, patrões, negociantes, mulheres, homens, crianças, } \\
\text { adultos). }\end{array}$ \\
\hline
\end{tabular}

Fonte: elaborado pela autora, 2015.

Nota-se que o elemento mais recorrente nas categorias esboçadas é o agente, isto é, o indivíduo, força principal da ação, aquele que produz no espaço do campo, no mar, no espaço rural, urbano ou marítimo, e que faz circular, vende, idealiza, registra, representa, reproduz, materializa com suas ferramentas e que encerra os processos de criação. Contudo, a decadência produtiva do café evidenciou a grande expressão do rebaixamento da autoestima humana frente à luta contra os riscos naturais e humanos, ou das forças econômica e históricas, incidentes na produção cafeeira.

A representação do poder econômico e social está explicitamente interpretada na construção da paisagem, que também insere a ruína econômica como uma das drásticas consequências sociais, além dos efeitos naturais em decorrência de fatores diversos como a geada, a queimada, as pragas, problemas na manutenção e o fracasso da produção cafeeira, as crises políticas etc., podendo ser assim indicados, ordenados em pontos de análise e interpretação:

- a mentalidade do proprietário dos bens e meios de produção surge impregnada na paisagem, tornando verificável a aderência de sustentação do exercício do poder político e econômico dos agentes em cena;

- a paisagem cafeeira é também identidade do capital, do lucro, da produção e circulação do café em direção a outros territórios de mercado e consumo;

- a perspectiva a serviço do registro da produção do trabalhador da terra e da lucratividade do proprietário da terra. 
Fontes comparativas são reunidas a partir de gêneros documentais diversos: fotografias, cartões postais, livros de registros de fazendas em acervos institucionais, como a Coleção Bolsa do Café de São Paulo, ofícios diversos etc., além dos chamados "sebos e antiquários". 3

- a perspectiva das manchas territoriais, dos corredores e matrizes;

- a cultura do senhor de terras "impregnada" na paisagem dos significados de organização espacial;

- o enquadramento do escravo, do imigrante e do ex-escravo como indicativo de propriedade, prosperidade e domesticação humana, que avança além da representação da imagem da paisagem cafeeira e é fartamente encontradas nos mapas, livros de registro da produção da paisagem do trabalho, álbuns de família, acervos ainda não explorados pelos pesquisadores;

- perspectiva histórica na ideia da modernidade e da larga produção e mecanização ao longo do século XX.

Confrontam-se elementos a partir da reflexão teórica da área da Ciência da Informação a respeito do escopo analítico das informações qualitativas referentes às atribuições (ou categorias) de espaço e paisagem presentes, neste estudo, ao longo da história da produção do café.

\section{Considerações finais}

O caminho percorrido até aqui indica que uma pequena parte da produção de pesquisas abrange estudos derivados de projetos voltados à análise da paisagem do café a partir do documento de acervo, quer dizer, do tratamento da unidade documental, seja ela impressa ou digital, desde que funcione como suporte da imagem da paisagem do café, atualmente representada nos mais diversos meios.

Foram evidenciados os elementos de composição da imagem referida: território, dimensão, imensidão, produção e ocupação humana mostraram-se fundamentais para unir os pressupostos da identidade informacional, as atribuições semânticas e as razões pelas quais se ajustam no estudo e resultam 
na tentativa de contribuição de renovação da leitura e postura analítica da paisagem rural e urbana do estudo relacionado ao café.

Espera-se que este intento, que compreende questões fundamentadas no desenvolvimento da Ciência da Informação, reitere a importância e a necessidade de trânsito entre disciplinas teóricas e a prática documental de maneira integradora e renovadora dos conhecimentos produzidos. Assim, a partir das reflexões sobre a pesquisa relacionada ao tema café, este trabalho visou contribuir para a compreensão da necessidade cada vez maior de o profissional da informação munir-se de conhecimentos de diferentes áreas para a compreensão do entorno.

Conclui-se que são inferidos conceitos da imagem da paisagem do café para subsidiar a pesquisa ao reconhecer o conhecimento científico e cultural destinado à reflexão, à análise, à organização e ao acesso informacionais no âmbito temático da produção na agricultura, no mercado e voltado ao consumidor da bebida.

\section{Referências}

ARAÚJO, C. A. Á. Fundamentos da ciência da informação: correntes teóricas e o conceito de informação. Perspectivas em Gestão \& Conhecimento, João Pessoa, v. 4, n. 1, p. 57-79, jan./jun. 2014. Disponível em: http://periodicos.ufpb.br/ojs2/index.php/pgc. Acesso em: 31 out. 2018.

BENINCASA, V. Velhas Fazendas: Arquitetura e Cotidiano nos Campos de Araraquara. São Paulo: Imprensa Oficial. 2003

CAMUS, A. A inteligência e o cadafalso. Rio de Janeiro: Editora Record, 2018.

CARVALHO, V. A representação da natureza na pintura e na fotografia brasileiras do século XIX. In: FABRIS, T. Fotografia: usos e funções no século XIX. São Paulo: Edusp, 1991. (Coleção texto \& arte, v. 3)

CORSATTO, C. A.; HOFFMANN, W. A. M. A produção do conhecimento científico, tecnológico e organizacional no contexto da geração de inovação e sua relação com a ciência da informação. In: Anais... XVI Encontro Nacional de Pesquisa em Ciência da Informação (ENANCIB), João Pessoa, Paraíba, out. 2015. Disponível em: http://www.ufpb.br/evento/index.php/enancib2015/ enancib2015/paper/viewFile/2804/1164. Acesso em: 02 fev. 2019. 
FREIRE, G. H. Ciência da informação: temática, histórias e fundamentos. Perspect. ciênc. inf., Belo Horizonte, v. 11, n. 1, p. 6-19, abr. 2006. DOI: http://dx.doi.org/10.1590/S1413-99362006000100002

FOSKETT, D. J. Informática. In: GOMES, H. E. (Org.). Ciência da Informação ou informática?. Rio de Janeiro: Calunga, 1980.

GOMBRICH, E. H. J. História da Arte. São Paulo: Editora LTC, 2000.

MACAMBYRA, M. Manual de Catalogação de Filmes da Biblioteca da ECA. São Paulo: Serviço de Biblioteca e Documentação da ECA, 2009. Disponível em: http://www.rebeca.eca.usp.br/Manuais/Manual_de_catalogacao_de_filmes.pdf. Acesso em: 02 fev. 2019.

MANINI, M. P. Análise documentária de fotografias: um referencial de leitura de imagens fotográficas para fins documentários. 2002. 226 f. Tese (Doutorado em Ciências da Comunicação) - Departamento de Biblioteconomia e Documentação, Universidade de São Paulo, São Paulo, 2002. Disponível em: http://www.teses.usp.br/teses/disponiveis/27/27143/tde-23032007-111516/ptbr.php. Acesso em: 10 fev. 2019.

MONTEIRO, S. D.; ROSA, C. M.; VIDOTTI, S. A. B. G. A busca e o eye tracking: um olhar semiótico sobre o knowledge graph. Em Questão, Porto Alegre, v. 26, n. I, p. 304-326, jan/abr. 2020. Disponível em: https://www.seer.ufrgs.br/EmQuestao/article/view/88844/54348. Acesso em: 20 de fev. 2020.

PANOFSKY, E. Iconografia e iconologia: uma introdução ao estudo da arte da Renascença. In: PANOFSKY, Erwin. Significado nas artes visuais. 3. ed. São Paulo: Perspectiva, 2007. cap. 1.

PIGNATARI, D. Semiótica \& literatura. 6. ed. São Paulo: Ateliê Editorial, 2004.

SARACEVIC, T. Ciência da Informação: origem, evolução e relações.

Perspectivas em Ciência da Informação, v. 1, n. 1, p. 41-62, jan./jun. 1996.

Disponível em:

http://portaldeperiodicos.eci.ufmg.br/index.php/pci/article/view/235/22. Acesso em: 20 de fev. 2020.

SISTEMA ESTADUAL DE ANÁLISE DE DADOS (SEADE). Anuário Estatístico da Superintendência dos Serviços do Café do Estado de São Paulo. São Paulo: Biblioteca Digital SEADE, 2018. Disponível em: http://produtos.seade.gov.br/produtos/bibliotecadigital/view/\#2. Acesso em: 07 dez. 2018. 


\title{
Analysis of represented coffee landscape: interdisciplinary views
}

\begin{abstract}
The present article operates the reading of the document from the a priori elements of the analysis of the landscape image, in face of the empirical experience, subsidiary of the observation of the selected documentary object. This study presents three objectives: how to collect information from documents related to historical collections, analysis of cultural contexts and arguments that point to a reflection of the interdisciplinary articulation between areas of the humanities. For this research the quadripolar method is applied in the study of cultural contexts, between the morphological, practical, epistemological and theoretical poles. The conclusion is that by emphasizing the articulation and elements arising from the quadripolar investigative dynamics, it is possible to problematize the linear reading of the landscape in the theme of coffee to new scientific and cultural approaches.
\end{abstract}

Keywords: Landscape. Coffee. Document Analysis. Quadripolar method.

Recebido: 06/04/2020

Aceito: $17 / 07 / 2020$

\section{Declaração de autoria}

Concepção e elaboração do estudo: Silvia Maria do Espírito Santo

Coleta de dados: Silvia Maria do Espírito Santo

Análise e discussão de dados: Silvia Maria do Espírito Santo

Redação e revisão do manuscrito: Silvia Maria do Espírito Santo

\section{Como citar}

ESPÍRITO SANTO, Silva Maria do. Análise da paisagem cafeeira representada: visões interdisciplinares. Em Questão, Porto Alegre, v.27, n. 1, p. 91-110, 2021. Doi: http://dx.doi.org/ 10.19132/1808-5245271.91-110

\footnotetext{
1 Freire (2006, p. 12) analisa o crescimento da área simultaneamente à oscilação e ao afastamento entre campos do conhecimento, recorrendo a autores que o precederam: "Saracevic, por exemplo, aponta três características gerais que constituem a ciência da informação: interdisciplinaridade, ligação inexorável com a tecnologia de informação e, por último, uma participação ativa e deliberada na evolução da sociedade da informação" (SARACEVIC, 1996, p?). Isso tem levado a estudos epistemológicos relacionados à abordagem interdisciplinar que buscam mapear as relações entre a ciência da informação e outras áreas científicas. Estas relações são dinâmicas e podem ser mais fortes em um determinado tempo e espaço com algumas áreas científicas, enquanto que, com muitas outras, serão fracas ou ainda irão surgir pontos de interseção. Isso não quer dizer que não existam as áreas seminais, como a biblioteconomia, a computação, a comunicação, a psicologia e a linguística (FOSKETT, 1980).

${ }^{2}$ Referimo-nos ao traço mais bem naturalista ou realista na representação na Arte e na Literatura, resultando na inclusão do domínio de representações ou situações similares no plano artístico: "devemos pensar em Camus como ensaísta, dentro da linguagem especificamente
} 
francesa de Pascal e Chamfort - autores que, na impossibilidade de darem conta do desarrazoado do mundo, transformam suas meditações em retratos da condição humana, retratos que encontram seu ponto de apoio numa lapidação formal que os aproxima da tessitura literária" (PINTO, Manual Costa da. In: CAMUS, 2018, p. 10).

3 Ver Guia do Acervo (http://icaatom.arquivoestado.sp.gov.br/ica-atom/destaques.php) do Arquivo do Estado de São Paulo (1578-1822), que possui requerimentos, ofícios e extratos de Ordem. Atualmente conta 10.000 latas, 12.000 volumes de documentos avulsos e 22.000 volumes encadernados. Possui também o catálogo impresso da Bolsa Oficial do Café, comum em outros fundos. 